\title{
An antiserum against protamines for immunohistochemical studies of histone to protamine transition during human spermiogenesis*
}

\author{
Ch. Roux, M. Gusse†, Ph. Chevaillier† and J. P. Dadoune \\ Groupe d'Etude de la Formation et de la Maturation du Gamète Mâle et Laboratoire \\ d'Histologie-Embryologie, Faculté de Médecine Broussais-Hôtel Dieu, UER Biomédicale, \\ 45 rue des Saints-Pères, 75270 Paris, France, and $\nmid$ Laboratoire de Biologie Cellulaire, \\ Université Paris-Val de Marne, 94010 Créteil, France
}

\begin{abstract}
Summary. Specific polyclonal antisera have been obtained against total human protamines isolated from purified sperm nuclei. The specificity of antibodies was assessed in immunodotting and immunoblotting assays. In this preliminary report, these specific antibodies were used as probes for in-situ determination of histone to protamine transition during human spermiogenesis. Protamine-containing sites were detected on sections of human testes by light microscopy using the immunoperoxidase technique. As in other mammals, protamines appear and concentrate in condensed nuclei of elongating spermatids, i.e. during the later steps of human spermiogenesis.
\end{abstract}

Keywords: human sperm protamines; immunohistochemistry; histone-protamine transition; spermiogenesis

\section{Introduction}

During spermiogenesis, morphological changes of spermatid nuclei are concomitant with modifications of the basic protein complement associated with deoxyribonucleic acid. Somatic-type histones present in the early steps of spermiogenesis are generally replaced by more basic proteins enriched in arginine, termed intermediate proteins or protamines, depending on their properties. Protamines have very low molecular weight and some of them are cystein-rich (Monesi, 1964; Geremia et al., 1976; Loir \& Lanneau, 1978; Meistrich et al., 1978; Rodman et al., 1979; Grimes, 1986).

In some species, biochemical studies of nuclear protein transitions have been carried out on purified fractions of germ cells at different steps of spermiogenesis (Fawcett et al., 1971; Romrell et al., 1976; Bouvier, 1977; Meistrich et al., 1981; Balhorn et al., 1984).

However, the difficulties in obtaining human testes and purified fractions of intermediate and old spermatids do not yet permit biochemical analysis of nuclear basic proteins during spermiogenesis. Several basic proteins have been extracted from human sperm heads (Tanphaichitr et al., 1981; McKay et al., 1985, 1986). Recently, histones, protamines and a third group of proteins with intermediate molecular properties have been isolated and characterized (Gusse et al., 1986).

Protamines are generally considered as poor immunogens. Nevertheless, antibodies against human protamines can be detected in some autoimmune diseases, in infertile and vasectomized men (Samuel, 1978; Samuel et al., 1978).

The purpose of this preliminary work was to produce an antiserum against purified human protamines whose specificity was ascertained by immunoblotting. Subsequently, this antiserum was used to localize protamines in human germ cells with immunohistochemical techniques.

\footnotetext{
*Reprint requests to Professor J. P. Dadoune.
} 


\section{Materials and Methods}

Purification of human sperm protamines. Ejaculates were collected from donors assessed as normal from their spermogram and spermocytogram: sperm counts were $>20 \times 10^{6} / \mathrm{ml},>50 \%$ of spermatozoa were motile and $<50 \%$ were morphologically abnormal. The samples were preserved at $-80^{\circ} \mathrm{C}$, pooled and washed three times in the following medium: $20 \mathrm{~mm}$-Tris- $\mathrm{HCl} \mathrm{pH} \mathrm{7.5,} 150 \mathrm{~mm}-\mathrm{NaCl}, 0.25 \mathrm{M}$-sucrose, $2 \mathrm{~mm}$-EDTA, $0.5 \mathrm{~mm}$ phenylmethylsulphonyl fluoride, and $0.2 \%$ diisopropyl-fluorophosphate. Isolation and purification of basic nuclear proteins were performed as described previously (Gusse et al., 1986).

Briefly, sperm heads were separated from tails by sonication and demembranated with CHAPS (3-[(3cholamidopropyl) dimethylammonio]-1-propane-sulphonate). Acid-soluble proteins were extracted after reduction and alkylation and purified on carboxymethylcellulose.

Preparation of the antisera. Lyophilized purified human protamines $(900 \mu \mathrm{g})$, including HPla, HPIb, HP2, HP3 and $\mathrm{HP} 4$ fractions, were dissolved in a sterile solution of $150 \mathrm{mM}-\mathrm{NaCl}$ at $0^{\circ} \mathrm{C}$. Proteins were precipitated by adding three volumes of $0.01 \%(\mathrm{w} / \mathrm{v})$ methylated bovine serum albumin in distilled water (Benoit et al., 1982). The antigenic solution was emulsified with $3.5 \mathrm{ml}$ Freund's complete adjuvant containing I mg killed Mycobacterium tuberculosis $/ \mathrm{ml}$ (Sigma Chemical Company, St Louis, MO, U.S.A.) and electrically homogenized at $0^{\circ} \mathrm{C}$. Three male rabbits, aged $3 \cdot 5$ months, were intradermally and subcutaneously injected at several sites with about $300 \mu \mathrm{g}$ human protamines. At 31 , 45 and 60 days after the first injection, rabbits received one booster injection of $100 \mu \mathrm{g}$ protamines prepared in the same conditions as above. Antibody production was checked every week for 10 weeks by bleeding at the marginal ear vein. Undiluted antisera were stored below $-70^{\circ} \mathrm{C}$.

Immunodetection procedures and specificity controls. Dot-immunobinding assays were carried out according to the method of Hawkes et al. (1982): $0.5 \mu \mathrm{l}$ of a $0.01-0.05 \%(\mathrm{w} / \mathrm{v})$ antigenic solution of total basic nuclear proteins, of sperm-specific histones or of purified protamines was spotted on a $0.45 \mu \mathrm{m}$ nitrocellulose filter (Schleicher \& Schuell, Dassel, West Germany) by using a $10 \mu \mathrm{l}$ Hamilton syringe. After drying, sheets of nitrocellulose were stored at $-20^{\circ} \mathrm{C}$. Strips of nitrocellulose were neutralized by blocking non-specific antibody-binding sites with PBS-gelatinTween (PGT) containing $0.3 \%(\mathrm{w} / \mathrm{v})$ gelatin (Sigma type II), $0.2 \%(\mathrm{v} / \mathrm{v})$ Tween 20 in PBS pH 7.2, for 20 min with mechanical shaking. The dots were covered with 1:2 to 1:200 diluted rabbit antiserum in PGT for $2 \mathrm{~h}$ to overnight, washed three times with PGT, and incubated in horseradish peroxidase (HRP)-labelled goat anti-rabbit IgG (Institut Pasteur, Paris, France) at a dilution of 1:500 for $90 \mathrm{~min}$. Peroxidase activity was revealed by $3,3^{\prime}$-diaminobenzidine (Sigma) or $o$-phenylenediamine (Sigma) staining.

The immunoblotting assays were performed according to the procedures described previously by Towbin $e t$ al. (1979) and Glass et al. (1981). Total basic nuclear proteins or carboxymethylcellulose-purified fractions were electrophoresed on acid urea $17 \%$ polyacrylamide gels (Gusse et al., 1983). Proteins were then electrotransferred onto two superimposed nitrocellulose sheets at $30 \mathrm{~V} / 200 \mathrm{~mA}$ for $1 \mathrm{~h}$ in $1 \%$ acetic acid. After saturation in PGT for $1 \mathrm{~h}$ at $37^{\circ} \mathrm{C}$ or overnight at $4^{\circ} \mathrm{C}$, the first sheet was used for immunodetection by incubation for $2 \mathrm{~h}$ to overnight with 1:100 rabbit antiserum and then washed several times in PGT. Peroxidase-conjugated goat antirabbit IgG (Institut Pasteur) was added to a dilution of 1:200 for $90 \mathrm{~min}$. After several washes in PGT, peroxidase activity was revealed using 3,3'diaminobenzidine. The second sheet was stained with $0.2 \%$ Red Ponceau S in $0.3 \%$ trichloroacetic acid for accurate localizations of protein fractions. To control antisera specificity, some dots and blots containing human sperm proteins were incubated either with preimmune serum or with anti-protamine immunoglobulins previously precipitated with an excess of protamines.

Immunohistochemistry. Testis samples were obtained from 25-40-year-old men with proven brain death. Some tissue blocks were sliced using a cryostat without fixation or after previous fixation by immersion in a solution of $4 \%$ paraformaldehyde in $0.12 \mathrm{M}$-phosphate buffer $\mathrm{pH} 7.2$ and rinsed overnight in the same buffer containing $8 \%$ sucrose. Other samples were fixed in $10 \%$ neutralized formol or in aqueous Bouin fixative and then embedded in paraffin wax (Cytoparaffin Microcolor $54^{\circ} \mathrm{C}$ ). Smears of sperm cells were air-dried or fixed in Carnoy's solution or methanol-acetone $(1: 1 \mathrm{v} / \mathrm{v})$. Some smears of cells were immersed for $3 \mathrm{~min}$ in the following solution to modify the chromatin structure: $2 \mathrm{M}$ guanidinum chloride ( $\mathrm{GuCl}$ ), $0.25 \mathrm{M}$-Tris- $\mathrm{HCl} \mathrm{pH} \mathrm{8.5,0.5 \%} \beta$-mercaptoethanol (Rodman et al., 1979). Sections and smears were sequentially incubated with the following antisera or reagents (Nakane \& Pierce, 1967): (1) 1:50 to 1:200 diluted rabbit antiserum in PBS for $1 \mathrm{~h}$ or overnight; (2) HRP-labelled goat anti-rabbit IgG (Institut Pasteur) at a dilution of $\mathrm{I}: 100$ for $\mathrm{I} h$; and (3) a freshly prepared solution of $0.05 \%$ diaminobenzidine and $0.01 \%$ hydrogen peroxide in PBS for $5 \mathrm{~min}$. After each incubation, the slides were rinsed in PBS for $15 \mathrm{~min}$ with three changes of the buffer. After the last wash, they were dehydrated, mounted in Eukitt and observed by light microscopy without counterstaining or after aqueous eosin staining for $1 \mathrm{~min}$ before dehydration. The indirect immunofluorescence technique was also used (Coons, 1958), and the second antibody was a fluorescein-isothiocyanate-conjugated goat antirabbit IgG at a dilution of 1:50 for $30 \mathrm{~min}$. Sections were mounted in buffered glycerine at $\mathrm{pH} 7.6$ and observed under a fluorescence microscope in epifluorescence configuration.

As immunohistochemical controls, some sections were incubated with labelled goat anti-rabbit antibody alone or with antiserum against human protamines previously treated with an excess of protamines. 


\section{Results}

Human sperm nuclei contain several basic proteins which can be classified into three families according to their molecular properties and electrophoretic mobilities (Gusse et al., 1986). Sperm histones are either somatic-like histones or testis-specific variants. Four molecular species of protamines called HP1, HP2, HP3 and HP4 have been purified, some of them being phosphorylated. The

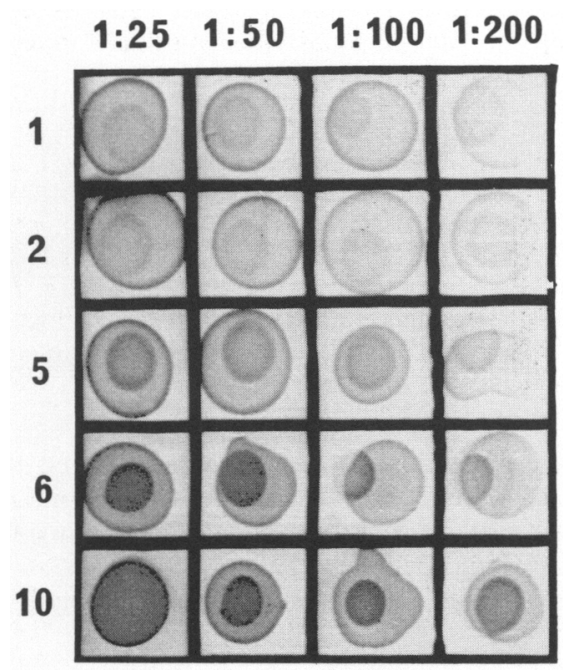

Fig. 1. Dot immunoassay for serum antibodies against total human sperm protamines at a concentration of $0.01 \%(w / v)$. A serial dilution assay of the serum $(1: 25$ to $1: 200)$ at weekly intervals is shown (1 to 10$)$.

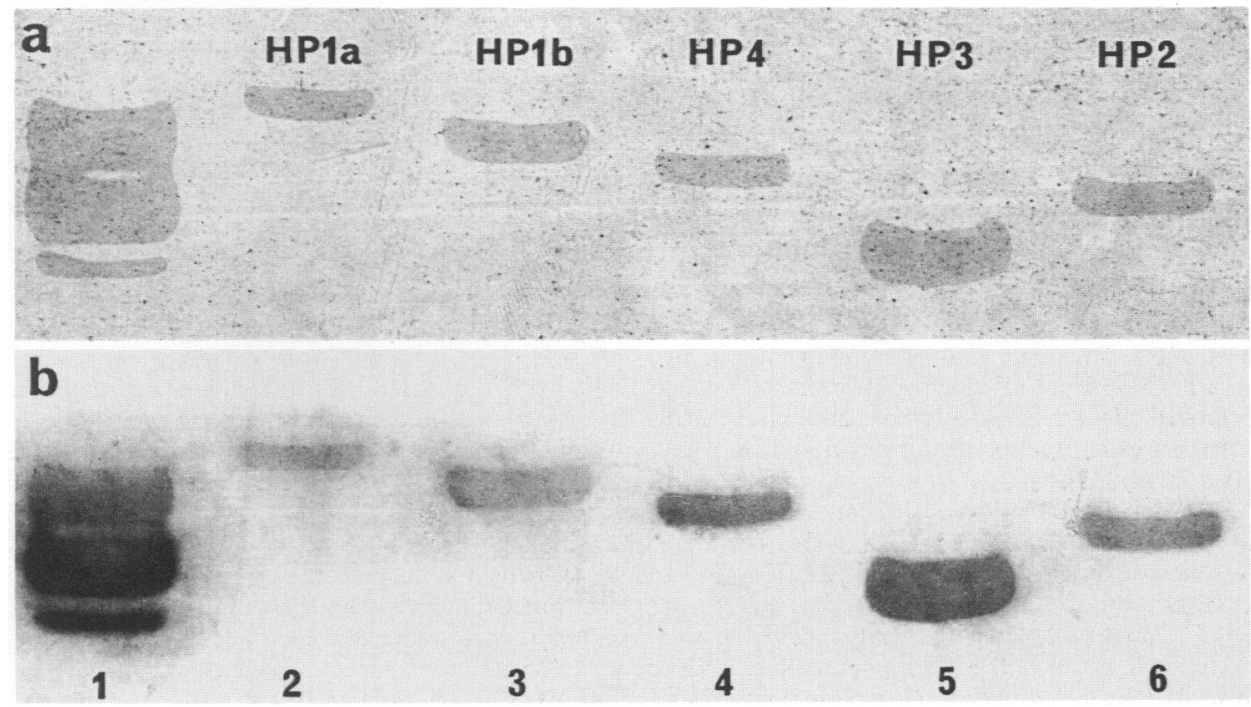

Fig. 2. Analytical polyacrylamide gel electrophoresis and immunoblotting of human sperm protamines: (a) electroblot on nitrocellulose (second sheet) stained with Red ponceau S; (b) immunoblot (first sheet of nitrocellulose). Lane 1: total human protamines used as antigenic mixture; lanes 2-6: purified human protamines. Equal amounts of proteins were loaded onto the polyacrylamide gel $(20 \mu \mathrm{g}$ per slot $)$. 


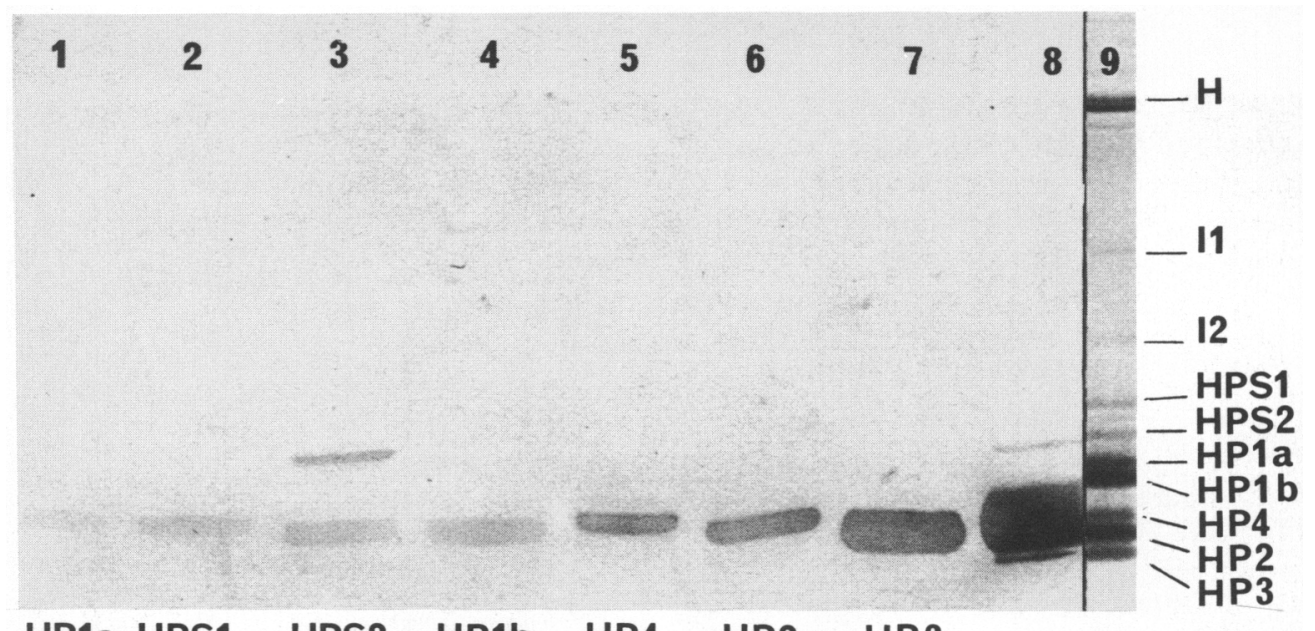

\section{HP1a HPS1 HPS2 HP1b HP4 HP2 HP3 HP1a HP1b}

Fig. 3. Electrophoresis ( $20 \mu \mathrm{g}$ proteins per slot) and immunoblotting of basic proteins extracted from human sperm nuclei. Lanes 1-7 represent immunoblots of the major fractions obtained during the purification of basic proteins by carboxymethylcellulose chromatography. Lane 8 is an immunoblot of total acid-soluble nuclear proteins. Lane 9 shows the electrophoretic pattern of total acid-soluble proteins from sperm nuclei stained with Coomassie brilliant blue.

third family of sperm-specific nuclear proteins is a group of five proteins (HP-I1, I2, I3, S1, S2) which have intermediate basicity and electrophoretic mobility between those of histones and those of protamines.

The presence of antibodies against human protamines in rabbit serum was shown by immunodots with immunoperoxidase staining. On the 7 th day after the first booster injection, a positive reaction was detected as a coloured dot against the white filter background after peroxidase staining. The staining of dots became more and more intense with time up to the last booster injection, thus suggesting an increase in the rabbit antibody titres. The antiserum reacted with pooled purified protamines (HP1, HP2, HP3, HP4) (Fig. 1), as well as with total basic nuclear proteins, but not with sperm-specific histone-like proteins. Reactions became negative after prior incubation of antiserum pretreated with human protamines. No reaction was observed with preimmune serum.

The immunoblot assays revealed that basic nuclear proteins extracted from human spermatozoa can be easily transferred from polyacrylamide gels to nitrocellulose. Antiserum bound specifically to all four protamines (Fig. 2). By contrast, neither histones nor intermediate proteins showed any immunoreactivity, except for one animal which developed antibodies reacting both with human protamines and with the intermediate protein HPS2 (Fig. 3). The detection of immuno-complexes was more sensitive after diaminobenzidine than after phenylenediamine staining.

The indirect immunoperoxidase technique on paraffin-wax sections revealed that only elongated spermatids with condensed nuclei presented strongly stained nuclei (Fig. 4). No preferential location in any part of the nuclei could be detected. Young spermatids with round nuclei remained unstained (Fig. 4). No staining was detected in the cytoplasm of any of these cells, in the other cells of the seminiferous epithelium (spermatogonia, spermatocytes, spermatozoa and Sertoli cells) or in the Leydig cells (Fig. 4). The indirect immunofluorescence technique gave similar results. On control sections, nuclei of intermediate and elongated spermatids were never stained. Without previous treatment, the same immunohistochemical methods applied to smears did not show any 

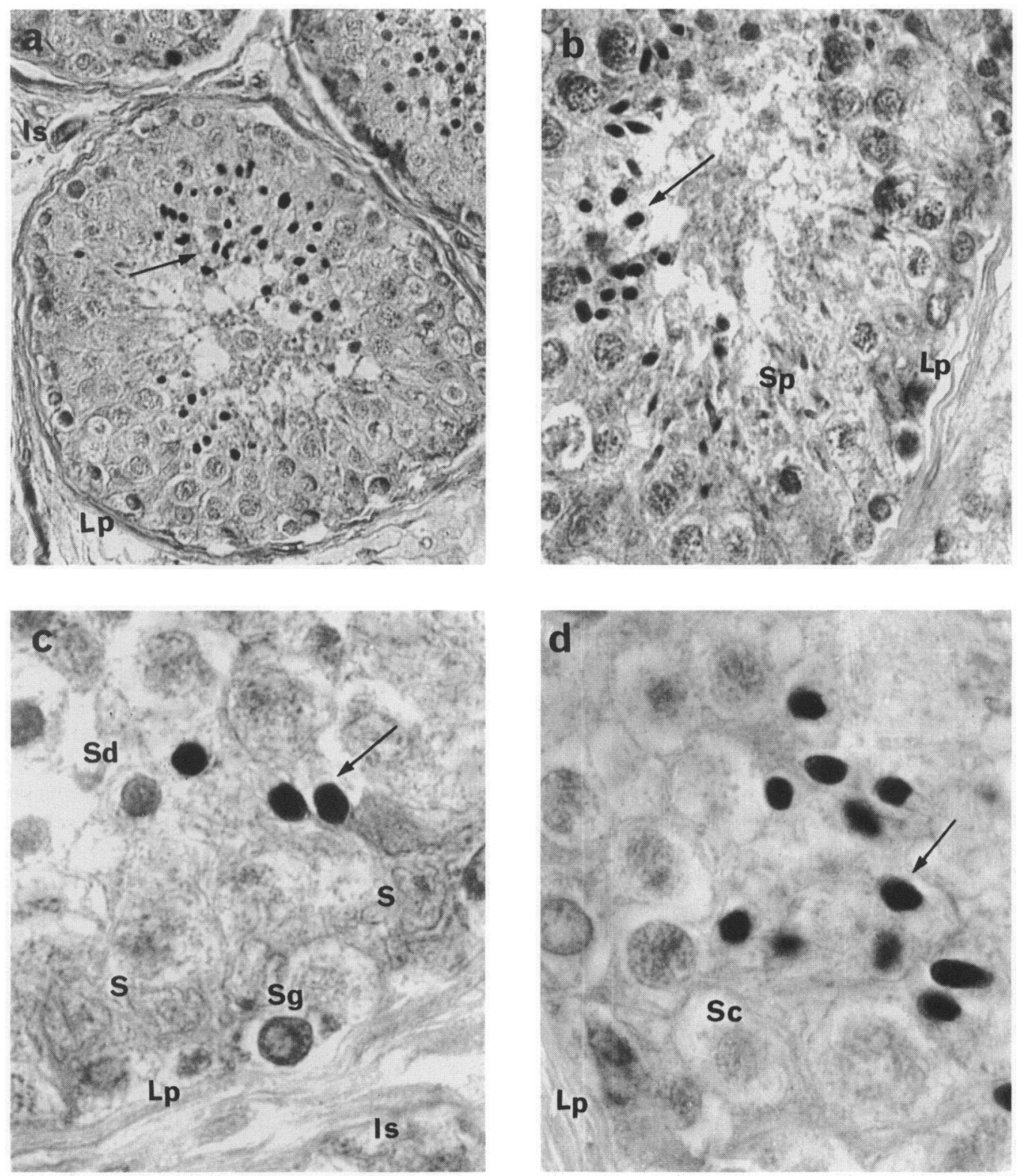

Fig. 4. Human testis, Bouin-fixed, stained by the indirect immunoperoxidase method with antihuman protamine antiserum. Slides were counterstained with aqueous eosin. In the seminiferous tubules, only late spermatids $(\rightarrow)$ with elongated nuclei are immunoreactive. All other cell structures which are observed on this figure are revealed only by their staining with eosin. No reaction is detected in the interstitial space (IS). $\mathrm{Sg}=$ spermatogonia; $\mathrm{Sc}=$ primary spermatocytes; $\mathrm{Sd}=$ round spermatids; $\mathrm{Sp}=$ spermatozoa; $\mathrm{S}=$ Sertoli cells; $\mathrm{L} p=$ lamina propria. a, $\times 500 ; \mathrm{b}, \times 750 ; \mathrm{c}, \mathrm{d}, \times 1500$. 
nuclear staining in ejaculated spermatozoa. The guanidinum chloride and $\beta$-mercaptoethanol solution induced sperm head swelling and these swollen sperm nuclei were stained by indirect immunohistochemical techniques (Fig. 5).
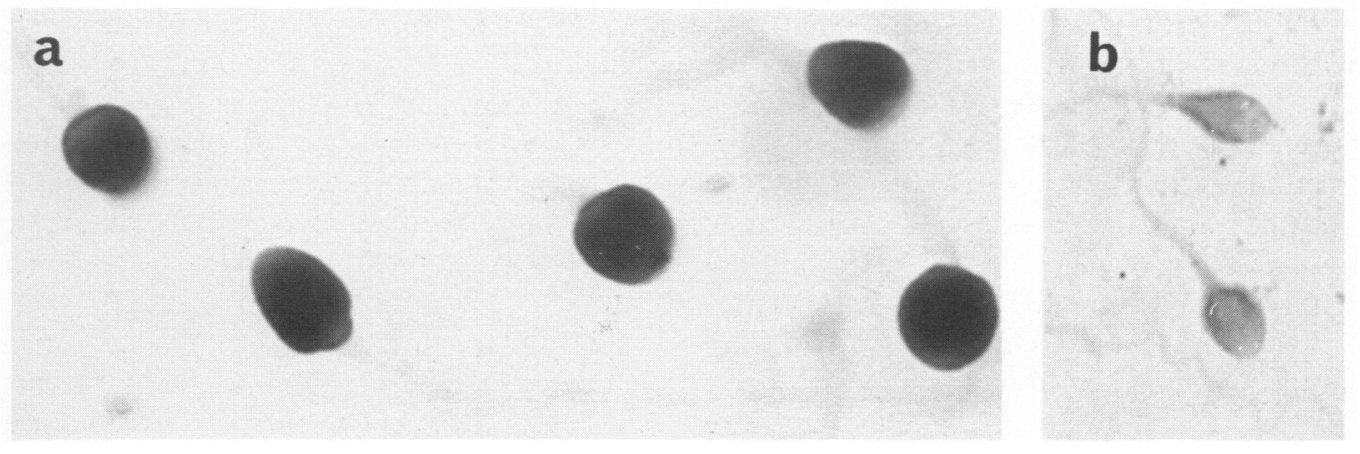

Fig. 5. Indirect immunoperoxidase method with antihuman protamine antiserum on smears of sperm cells fixed in Carnoy's solution. (a) Only ejaculated spermatozoa with swollen nuclei (treated by guanidinum chloride and $\beta$-mercaptoethanol) are immunoreactive. $\times 2000$. (b) Sperm cells without previous treatment of chromatin are unstained. $\times 2000$.

\section{Discussion}

Few reports have been published on the immunogenicity of protamines. Mouse sperm protamines (Rodman et al., 1982, 1984) as well as ram protamines (Courtens et al., 1983) appeared to be antigenic. Samuel (1978) and Samuel et al. (1978) showed that human protamines can also elicit the production of specific antibodies. The present data are in agreement with these conclusions. Immunodotting procedures which were used for qualitative and semiquantitative evaluation of antibody production after dilution of antisera (Hawkes et al., 1982) showed the specificity of rabbit antiserum against human sperm protamines. Immunostaining was negative when rabbit antisera previously immuno-absorbed on purified human sperm protamines, or preimmune sera were used. Immunoassays showed that the major protamines (HP1a, HP1b, HP2, HP3, HP4) are antigenically distinct both from the acid-soluble histone-like proteins and from the basic intermediate proteins HPI1, 12, I3 and S1. This lack of cross-reactivity between protamines and the other classes of nuclear basic proteins can be explained by their structural differences (Gaastra et al., 1978; McKay et al., 1985, 1986; Ammer et al., 1986; Gusse et al., 1986). The binding of HPS2 to an immunoserum was only obtained for one of the animals studied. In this case, binding might be related to crossreactivity with one of the major protamines or to a contamination of antigenic protamines by the HPS2 fraction which displays similar chromatographic characteristics. Complete or partial amino acid sequences of protamines HP2, HP3 and HP4 show strong homologies in their primary structure (McKay et al., 1985; 1986; Ammer et al., 1986; Gusse et al., 1986) whereas HP1 protamines appear structurally distinct. Therefore, although our antiserum contains a mixture of antibodies, we suggest that the major protamines (HP1, HP2, HP3, HP4) probably share antigenic sites. Purification of individual protamine fractions in large amounts would allow selective depletion of immunosera and production of specific antibodies against each protamine.

Staining was satisfactory with the indirect immunoperoxidase technique on paraffin-wax sections after fixation in aqueous Bouin. This fixative, which is usually used in immunoperoxidase methods (Baker \& Jaffe, 1975), contains picric acid which is known to precipitate small nuclear basic proteins (Bloch \& Hew, 1960; Bols et al., 1986). 
Immunocytochemical observations proved that the immunosera against protamines from ejaculated human spermatozoa reacted with nuclear proteins of elongated spermatids in human testis. Resolution by light microscopy is insufficient to identify accurately intermediate spermatids with elongating nuclei which appeared to be weakly stained. The precise steps of spermiogenesis at which antisera react will only be detected by immunocytochemical staining at the ultrastructural level. The increase of nuclear labelling at the late steps of spermiogenesis indicates that chromatin in spermatids is enriched in protamines, as has been shown by previous biochemical (Geremia et al., 1976; Loir \& Lanneau, 1978; Grimes, 1986) and autoradiographic (Monesi, 1964, 1967; Mayer \& Zirkin, 1979) studies in several mammals. These observations are in agreement with ultrastructural and cytochemical data suggesting that, in man, protamines first appear in condensed nuclei of spermatids at steps 5-6 (Dadoune \& Alfonsi, 1986). The lack of cytoplasmic labelling reinforces the hypothesis that protamines are not accumulated inside cytoplasm before their migration to the cell nucleus (Loir \& Lanneau, 1978).

The increase of immunoreactivity appeared to be concomitant with chromatin condensation in maturing spermatids. In contrast, nuclei of ejaculated spermatoza from untreated semen smears were not labelled, although the antigenic material was derived from sperm cells. It is well known that a number of disulphide bridges are formed between cysteine-rich nuclear proteins during epididymal transit, ensuring a stronger stability of DNA-protein complexes (Bedford et al., 1973). Consequently, intranuclear sites able to bind specific nuclear antibodies only become accessible by denaturation of nucleoproteins and chromatin decondensation, as has been shown previously (Samuel et al., 1978; Samuel, 1978; Rodman et al., 1979, 1982, 1984).

Our results show that specific antibodies against human sperm protamines can be used to demonstrate that the nuclear basic protein transition occurs during late spermiogenesis. The next step of the investigation will be purification of antibodies against individual protamine fractions to obtain more information on the timing of protamine deposition, screening human testis c-DNA libraries and examination of nuclear protein anomalies.

This work was done with the financial support of la Direction de la Recherche du Ministère de l'Education Nationale, La Fondation pour la Recherche Médicale and le Centre National de la Recherche Scientifique (RCP No. 680). We thank D. Tesson for preparation of the paper.

\section{References}

Ammer, H., Henschen, A. \& Lee, C.H. (1986) Isolation and amino acid sequence analysis of human sperm protamines PI and P2. Biol. Chem. Hoppe Seyler's 367, 515-522.

Baker, B.L. \& Jaffe, R.B. (1975) The genesis of cell types in the adenohypophysis of the human fetus as observed with immunocytochemistry. Am. J. Anat. 143, 137-162.

Balhorn, R., Weston, S., Thomas, C. \& Wyrobek, A.J. (1984) DNA packaging in mouse spermatids. Synthesis of protamine variants and four transition proteins. Expl Cell Res. 150, 298-308.

Bedford, J.M., Calvin, H.I. \& Cooper, G.W. (1973) The maturation of spermatozoa in the human epididymis. J. Reprod. Fert., Suppl 18, 199-213.

Benoit, R., Bohlen, P., Ling, N., Briskin, A., Esch, F., Brazeau, P., Ying, S.Y. \& Guillemin, R. (1982) Presence of somatostatin-28-(1-12) in hypothalamus and pancreas. Proc. natn. Acad. Sci. U.S.A. 79, 917-921.

Bloch, D.P. \& Hew, H.Y.C. (1960) Schedule of spermatogenesis in the pulmonate snail Helix aspersa with special reference to histone transition. J. Biophys. Biochem. Cytol. 8, 515-532.

Bols, N.C., Mann, M. \& Kasinsky, H.E. (1986) Detection of sperm histone diversity among vertebrates by alkaline fast green staining. Stain Technol. 61, 111-119.

Bouvier, D. (1977) Chemical aspects of histone acetylation and replacement in mouse spermatids at different stages of maturation. Cytobiologie 15, 420-437.

Coons, A.H. (1958) Fluorescent antibody methods. In General Cytochemical Methods, pp. 399 422. Ed. J. F. Danielli. Academic Press, New York.

Courtens, J.L., Delaleu, B., Dubois, M.P., Lanneau, M., Loir, M. \& Rozinek, J. (1983) Immunocytochemical localization of protamine in the spermatids of the ram. Gamete Res. 8, 21-28.

Dadoune, J.P. \& Alfonsi, M.F. (1986) Ultrastructural and cytochemical changes of the head components of human spermatids and spermatozoa. Gamete Res. 14, 33-46.

Fawcett, D.W., Anderson, W. \& Phillips, D.M. (1971) 
Morphologenetic factors influencing the shape of the sperm head. Devl Biol. 26, 220-251.

Gaastra, W., Lukkes-Hofstra, J. \& Kolk, A.H.J. (1978) Partial covalent structure of two basic chromosomal proteins from human spermatozoa. Biochem. Genet. 16, 525-529.

Geremia, R., Goldberg, R.B. \& Bruce, W.R. (1976) Kinetics of histone and protamine synthesis during meiosis and spermiogenesis in the mouse. Andrologia 8, $147-156$.

Glass, W.F., Briggs, R.C. \& Hnilica, L.S. (1981) Identification of tissue-specific nuclear antigens transferred to nitrocellulose from polyacrylamide gels. Science, $N . Y$. $211,70-72$.

Grimes, S.R. (1986) Nuclear proteins in spermatogenesis. Comp. Biochem. Physiol. 83B, 495-500.

Gusse, M., Sautière, P., Chauvière, M. \& Chevaillier, Ph. (1983) Extraction, purification and characterization of the sperm protamines of the dog-fish Scylliorhinus caniculus. Biochim. Biophys. Acta 748, 93-98.

Gusse, M., Sautière, P., Bélaiche, D., Martinage, A., Roux, C., Dadoune, J.P. \& Chevaillier, Ph. (1986) Purification and characterization of nuclear basic proteins of human sperm. Biochim. Biophys. Acta 884, $124-134$.

Hawkes, R., Niday, E. \& Gordon, J. (1982) A dotimmunobinding assay for monoclonal and other antibodies. Analyt. Biochem. 119, 142-147.

Loir, M. \& Lanneau, M. (1978) Partial characterization of ram spermatidal basic nuclear proteins. Biochem. Biophys. Res. Commun. 80, 975-982.

Mayer, J.F. \& Zirkin, B.R. (1979) Spermatogenesis in the mouse. I. Autoradiographic studies of nuclear incorporation and loss of ${ }^{3} \mathrm{H}$-amino acids. J. Cell Biol. 81, 403-410.

Meistrich, M.L., Brock, W.A., Grimes, S.R., Platz, R.D. \& Hnilica, L.S. (1978) Nuclear protein transition during spermatogenesis. Fedn Proc. Fedn Am. Socs exp. Biol. 37, 2522-2525.

Meistrich, M.L., Longtin, J., Brock, W.A., Grimes, S.R. \& Mace, M.L. (1981) Purification of rat spermatogenic cells and preliminary biochemical analysis of these cells. Biol. Reprod. 25, 1065-1077.

McKay, D.J., Renaux, B.S. \& Dixon, G.H. (1985) The amino acid sequence of human sperm protamine P1. Biosci. Rep. 5, 383-391.

McKay, D.J., Renaux, B.S. \& Dixon, G.H. (1986) Human sperm protamines Amino-acid sequences of two forms of protamine P2. Eur. J. Biochem. 156, 5-8.
Monesi, V. (1964) Autoradiographic evidence of a nuclear histone synthesis during mouse spermatogenesis in the absence of detectable quantities of nuclear ribonucleic acid. Expl Cell Res. 36, 683-688.

Monesi, V. (1967) Ribonucleic acid and protein synthesis during differentiation of male germ cells in the mouse. Archs Anat. microsc. Morphol. exp. 56, 61-74.

Nakane, P.K. \& Pierce, G.B. (1967) Enzyme-labeled antibodies for the light and electron microscopic localization of tissue antigens. J. Cell Biol. 33, 307-318.

Rodman, T.C., Litwin, S.D., Romani, M. \& Vidali, G. (1979) Life history of mouse sperm protein. Intratesticular stages. J. Cell Biol. 80, 605-620.

Rodman, T.C., Pruslin, F.H. \& Allfrey, V.G. (1982) Mechanisms of displacement of sperm basic nuclear proteins in mammals. An in vitro simulation of postfertilization results. J. Cell Sci. 53, 227-244.

Rodman, T.C., Pruslin, F.H. \& Allfrey, V. G. (1984) Protamine-DNA association in mammalian spermatozoa. Expl Cell Res. 150, 269-281.

Romrell, L.J., Bellve, A.R. \& Fawcett, D.W. (1976) Separation of mouse spermatogenic cells by sedimentation velocity A morphological characterization. Devl Biol. 49, 119-131.

Samuel, T. (1978) Differentiation between antibodies to protamines and somatic nuclear antigens by means of a comparative fluorescence study on swollen nuclei of spermatozoa and somatic cells. Clin. exp. Immunol. 32, 290-298.

Samuel, T., Kolk, A.H.J. \& Rumke, P. (1978) Studies on the immunogenicity of protamines in humans and experimental animals by means of a microcomplement fixation test. Clin. exp. Immunol. 33, 252-260.

Tanphaichitr, N., Sobhon, P., Chalermisarachai, P. \& Patilantakarnkool, M. (1981) Acid-extracted nuclear proteins and ultrastructure of human sperm chromatin as revealed by differential extraction with urea, mercaptoethanol, and salt. Gamete Res. 4, 297-315.

Towbin, H., Staehelin, T. \& Gordon, J. (1979) Electrophoretic transfer of proteins from polyacrylamide gels to nitrocellulose sheets: procedure and some applications. Proc. natn. Acad. Sci. U.S.A. 76, $4350-4354$. 